\title{
Diagnostic accuracy of the VibraTip in detection of diabetic peripheral neuropathy
}

\author{
HISHAM NIZAR, ${ }^{1}$ NEIL MUNRO, $1,2,3$ PETER NIGHTINGALE, ${ }^{4}$ MICHAEL D FEHER ${ }^{1,2,3}$
}

\begin{abstract}
Aims: Clinical assessment of peripheral neuropathy can be performed by testing vibration sense using a tuning fork and cutaneous sensation using a $10 \mathrm{~g}$ monofilament. The VibraTip $^{\circledast}$ is a novel device which produces a constant vibratory stimulus and therefore assesses vibration sense. This study evaluated the diagnostic accuracy of the VibraTip compared to the tuning fork.

Methods: From 100 patients with diabetes, 50 patients had confirmed peripheral neuropathy (PN +ve) and 50 were confirmed to have no peripheral neuropathy (PN -ve) as assessed by neurothesiometer. Both groups were then assessed using both the VibraTip and tuning fork. The sensitivity, specificity, predictive values and likelihood ratios for diagnosing peripheral neuropathy were calculated.

Results: A statistically significant difference in sensitivity $(52 \%)(p<0.001)$ between the VibraTip and tuning fork results was observed for PN +ve subjects. However no statistically significant difference in specificity $(6 \%)$ $(p<0.25)$ was seen for PN -ve subjects.

Conclusion: This study confirms that the VibraTip is comparable to the neurothesiometer, and superior to the tuning fork, in the detection of peripheral neuropathy and could be a useful screening tool in clinical practice.
\end{abstract}

Key words: VPT, peripheral neuropathy, VibraTip

\section{Introduction}

At the beginning of the 20th century the ability to detect vibration sense was recognised as a specific sensory modality. ${ }^{1-3}$ Tuning forks applied directly to the skin have been used to assess vibration sense. There are several drawbacks to the use of tuning forks in clinical practice. There is little agreement about the op-

Beta Cell Diabetes Centre, Chelsea \& Westminster Hospital, London, UK.

Diabetes Therapy Evaluation Network, London, UK.

CSRI, Warwick University, Warwick, UK

University Hospital Birmingham NHS Foundation Trust, Wellcome

Trust Clinical Research Facility, Birmingham, UK.

Address for correspondence: Dr Hisham Nizar

Beta Cell Diabetes Centre, Chelsea \& Westminster Hospital,

369 Fulham Road, London, SW10 9NH, UK

Tel: +44 (0)20 33155843

E-mail: nnizar@nhs.net

Br J Diabetes Vasc Dis 2014;14:26-29

http://dx.doi.org/10.15277/bjdvd.2014.005

$\begin{array}{ll}\text { Abbreviations and acronyms } \\ \text { HbA } 1 \text { c } & \text { glycated haemoglobin } \\ \mathrm{NPV} & \text { negative predictive value } \\ \mathrm{PPV} & \text { positive predictive value } \\ \mathrm{PN}+\mathrm{ve} & \text { peripheral neuropathy +ve } \\ \mathrm{PN}-\mathrm{ve} & \text { peripheral neuropathy -ve } \\ \text { VPT } & \text { vibration perception thresholds } \\ \text { V } & \text { volts }\end{array}$

timal vibration frequency to be used. The coldness of the metal tuning fork and the pressure required to impart vibration can impair the specificity of the test. In terms of utility, tuning forks tend to be rather bulky and not easily carried discreetly. Additionally, tuning forks produce a set pitch rather than a set amplitude and vary in vibration intensity depending on the force with which they are struck and the time that elapsed since they were struck. ${ }^{4}$ These features may collectively lead to confusion and increase the time required to make diagnoses. Importantly, there is no precedent for cleaning or autoclaving tuning forks, and there may be increased risk of infection. There is no agreement about an optimal pitch of vibration or consistent guidelines on the use of tuning forks in clinical practice.

By comparison, the Horwell neurothesiometer ${ }^{5}$ is a device, which provides a constant source of vibration to assess this specific sense (Figure 1). The amplitude can be adjusted as needed. It is considered the "gold standard" tool for assessing vibration sense to confirm peripheral neuropathy. However, it has significant limitations including non-portability and dependency on electricity or overnight charging for usage.

In recent years Professor Andrew Levy and colleagues from University of Bristol have developed a novel device for measuring vibration sense, the VibraTip. ${ }^{6}$ The VibraTip is a key fob-sized device that has been specifically designed to overcome the limitations of tuning forks, by providing a constant source of gentle vibration using a vibrating motor (as used in mobile phones and vibrating wet razors) powered by a mercury- and lithium-free button cell in a clean, sealed, disposable unit (Figure 2).

To date there have been only two studies ${ }^{7,8}$ evaluating the VibraTip. The first study ${ }^{7}$ assessed agreement between perception of the VibraTip, tuning fork and $10 \mathrm{~g}$ monofilament. This study revealed correlation of results with all the above three devices. The second study ${ }^{8}$ assessed the VibraTip, neurothesio- meter, Neurotip, tuning fork and $10 \mathrm{~g}$ monofilament where the threshold for identifying peripheral neuropathy by the neurothesiometer was set at $25 \mathrm{Volts}$. There has been no comparative evaluation with the neurothesiometer set at 20Volts to assess peripheral neuropathy. 
Figure 1. Horwell Neurothesiometer.

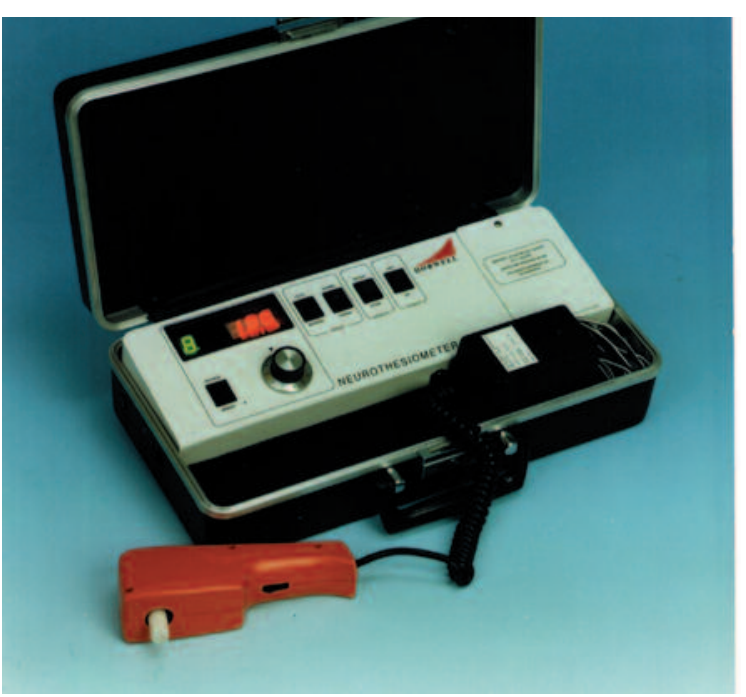

Reproduced courtesy of Scientifc Laboratory Supplies

Figure 2. VibraTip is a key fob sized device (a) which is used to assess sensitivity to vibration (b)

(a) VibraTip

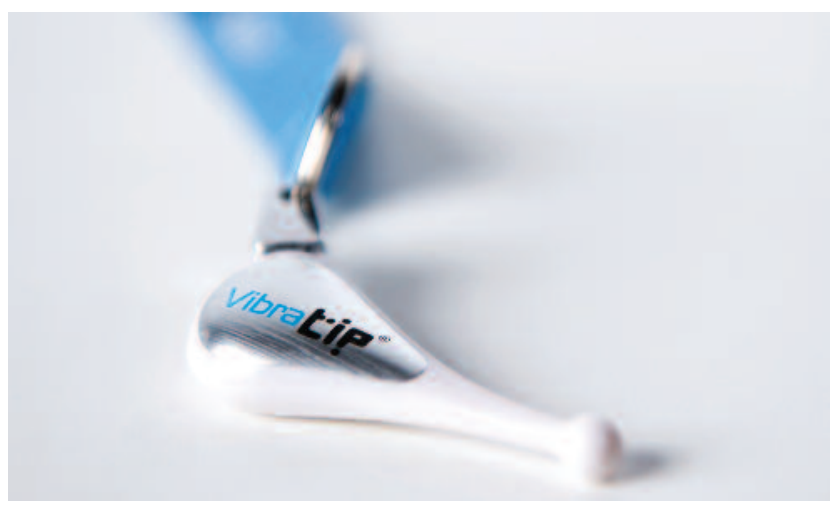

Reproduced courtesy of Danny O'Connell, McCallan Medical

(b) Use of VibraTip to assess vibration sense

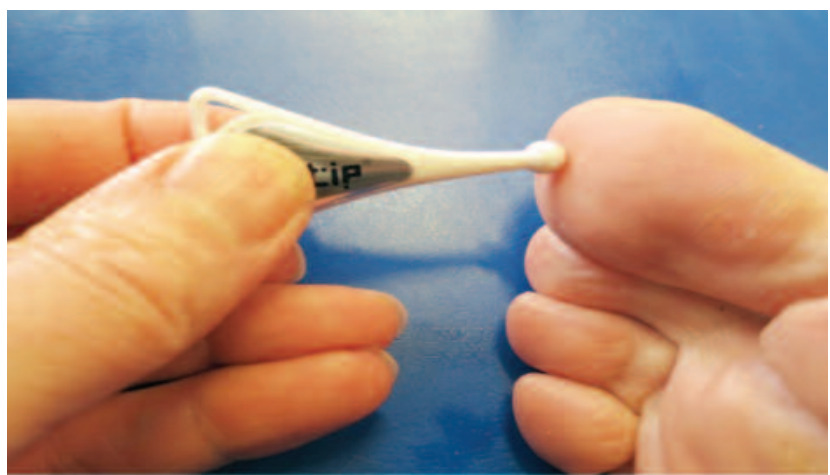

Reproduced courtesy of Professor Andy Levy, University of Bristol

\section{Aims}

The aim of our study was to assess the sensitivity and specificity of the VibraTip compared with that of a tuning fork in those patients with peripheral neuropathy confirmed by neurothesiometer set at 20Volts.

\section{Methods}

This study was a cross sectional observational design. Patients with either Type 1 diabetes or Type 2 diabetes were recruited from a secondary care specialist diabetes outpatient clinic. The following demographic details of each patient were recorded: duration of diabetes, type of diabetes, diabetes specific complications (retinopathy, nephropathy, neuropathy, ischaemic heart disease, cerebrovascular disease), latest $\mathrm{HbA}_{1 \mathrm{c}}$ measurement, current diabetes therapy and alcohol consumption.

The study had ethical approval and all those recruited gave written informed consent.

\section{Clinical assessment}

The presence of peripheral neuropathy was confirmed by the neurothesiometer set at 20Volts. The first clinical assessment was with the neurothesiometer to determine the presence of peripheral neuropathy. Following this, both the tuning fork and VibraTip were used to evaluate peripheral neuropathy and the results with each device were recorded.

We tested each patient first without the device activated and then with activation. Patients acknowledging the presence of vibration sense while the device was inactive were considered malingering. This helped us identify malingering patients who were excluded from the study. The vibration sense with all three devices was first demonstrated on the patient's forehead and then later used on the feet to assess for peripheral neuropathy.

All devices were tested on the same anatomical site, which was located on the left or right medial malleoli. Due to practical considerations, if this site could not be used then an alternative site was located on the lateral aspect of the first metatarsal head.

\section{Data analysis}

Patients were categorised into two groups according to the presence of peripheral neuropathy (PN +ve) or absence of peripheral neuropathy (PN -ve) based on the assessment by the neurothesiometer set at 20Volts. These two groups were then assessed with the VibraTip and a tuning fork. Data were evaluated to confirm the diagnostic accuracy of the presence of peripheral neuropathy.

In order to achieve statistical significance and adequate power, the sample size required was 100 . These sample sizes provided $95 \%$ confidence that the estimates of sensitivity and specificity (expressed as percentages) are within 15 of the true values. The requirement was 50 PN +ve subjects and 50 PN -ve subjects as identified by neurothesiometer.

\section{Results}

From the two clinical groups assessed, PN +ve patients were slightly older and had longer duration of diabetes than PN -ve patients (Table 1). 
Table 1 Demography of patients assessed for peripheral neuropathy determined by neurothesiometer (20V)

\begin{tabular}{|lll}
\hline & $\begin{array}{l}\text { Peripheral } \\
\text { neuropathy +ve } \\
(\mathbf{n = 5 0 )}\end{array}$ & $\begin{array}{l}\text { Peripheral } \\
\text { neuropathy -ve } \\
(\mathbf{n}=50)\end{array}$ \\
\hline Age (yrs) & $\begin{array}{l}\text { Mean 67 } \\
\text { (range 40-90) }\end{array}$ & $\begin{array}{l}\text { Mean 51 } \\
\text { (range 17-85) }\end{array}$ \\
\hline Gender & $\begin{array}{l}\text { Female } \mathrm{n}=13 ; \\
\text { Male } \mathrm{n}=37\end{array}$ & $\begin{array}{l}\text { Female } \mathrm{n}=19 ; \\
\text { Male } \mathrm{n}=31\end{array}$ \\
\hline Body mass index & $\begin{array}{l}\text { Mean 30.6 } \\
\text { (range 17-44) }\end{array}$ & $\begin{array}{l}\text { Mean 29.5 } \\
\text { (range 18-52) }\end{array}$ \\
Type 1 diabetes & $\mathrm{n}=10$ & $\mathrm{n}=20$ \\
\hline Type 2 diabetes & $\mathrm{n}=40$ & $\mathrm{n}=30$ \\
\hline HbA $\mathbf{1 c}$ (mmol/mol) & $\begin{array}{l}\text { Mean 69 } \\
\text { (range 39-130) }\end{array}$ & $\begin{array}{l}\text { Mean 70 } \\
\text { (range 37-151) }\end{array}$ \\
\hline Duration of diabetes (yrs) & $\begin{array}{l}\text { Mean 20.5 } \\
\text { (range 1-55) }\end{array}$ & $\begin{array}{l}\text { Mean 16.35 } \\
\text { (range 0.08-50) }\end{array}$ \\
\hline
\end{tabular}

The results of the clinical assessment using the VibraTip and the tuning fork are shown in Table 2. The assessments were stratified according to the presence (+ve) or absence (-ve) of peripheral neuropathy as determined by the neurothesiometer.

The sensitivity, specificity, positive predictive and negative predictive values and positive likelihood ratios for VibraTip and tuning fork are shown in Table 3.

In PN +ve subjects a significant difference in sensitivity of $52 \%(92-40)(p<0.001)$ between the VibraTip and tuning fork was noted. However no significant difference in specificity $6 \%$ $(100-94)(p<0.25)$ was seen for PN -ve subjects.

\section{Discussion}

Vibration sensation has been described to be the first modality of sensation to be lost in the development of diabetic peripheral neuropathy. This study has confirmed the diagnostic accuracy of the VibraTip in comparison to the tuning fork in the diagnosis of diabetic peripheral neuropathy. Both of these methods assess vibration sense, which is the clinical assessment of large fibre neuropathy, an early clinical sign in diabetic peripheral neuropathy. In comparison, small fibre neuropathy is clinically manifested by dysfunction or pain and temperature (Table 4).

Our study has assessed the devices (i.e. VibraTip, tuning fork and neurothesiometer) testing only vibration sense. We used a lower threshold of 20Volts for the confirmation of peripheral neuropathy compared to $25 \mathrm{Volts}$ used in the previous study. ${ }^{8}$ This loss of vibration sense could therefore be recognised at a much earlier stage, providing opportunity to prevent complications.

The VibraTip has clear utility advantages which include being portable, discreet to carry, and providing a constant source of vibration at a set amplitude. These utility advantages overcome several drawbacks encountered with the use of a tuning fork.

Two previous studies have evaluated the VibraTip. ${ }^{7,8}$ The pre-
Table 2 Assesment for peripheral neuropathy with (a) VibraTip and (b) tuning fork in subjectss with neurothesiometer confirmed presence (+ve) or absence (-ve) of peripheral neuropathy.

\begin{tabular}{|c|c|c|}
\hline \multicolumn{3}{|l|}{ (a)-VibraTip } \\
\hline & $\begin{array}{l}\text { Peripheral } \\
\text { neuropathy +ve }\end{array}$ & $\begin{array}{l}\text { Peripheral } \\
\text { neuropathy -ve }\end{array}$ \\
\hline VibraTip +ve & 46 & 3 \\
\hline VibraTip -ve & 4 & 47 \\
\hline \multicolumn{3}{|l|}{ (b)-Tuning Fork } \\
\hline & $\begin{array}{l}\text { Peripheral } \\
\text { neuropathy +ve }\end{array}$ & $\begin{array}{l}\text { Peripheral } \\
\text { neuropathy -ve }\end{array}$ \\
\hline Tuning Fork +ve & 20 & 0 \\
\hline Tuning Fork -ve & 30 & 50 \\
\hline
\end{tabular}

Table 3 Sensitivity, specificity, positive predictive and negative predictive values and positive likelihood ratios of peripheral neuropathy assessed by Vibratip and tuning fork.

\begin{tabular}{lll} 
& VibraTip & Tuning fork \\
Sensitivity & $92 \%$ & $40 \%$ \\
$\mathbf{( 9 5 \% ~ C l ) ~}$ & $(80.8-97.8 \%)$ & $(26.4-54.8 \%)$ \\
\hline $\begin{array}{l}\text { Specificity } \\
\mathbf{( 9 5 \% ~ C l ) ~}\end{array}$ & $94 \%$ & $100 \%$ \\
PPV & $(83.4-98.7 \%)$ & $(92.9-100 \%)$ \\
NPV & $94 \%$ & $100 \%$ \\
Positive likelihood ratios & 15.3 & $63 \%$ \\
& & Infinity
\end{tabular}

Table 4 The clinical features of both large and small fibre neuropathy.

$\begin{array}{ll}\begin{array}{l}\text { LARGE FIBRES } \\ \text { (myelinated fibres) }\end{array} & \begin{array}{l}\text { SMALL FIBRES } \\ \text { (unmyelinated fibres) }\end{array} \\ \text { Clinical features } & \begin{array}{l}\text { Clinical features } \\ \text { Weakness }\end{array} \\ \text { Wasting } & \begin{array}{l}\text { Pain } \\ \text { Tutonomic } \\ \text { Thermal }\end{array} \\ \text { Impaired vibration } & \text { Normal strength \& reflexes } \\ \text { Loss of joint position sense } & \\ \text { Loss of reflex } & \end{array}$

liminary study ${ }^{7}$ assessed several clinical devices including the VibraTip, $10 \mathrm{~g}$ monafilament and tuning fork. There was good correlation of results among all three devices. However, the study ${ }^{8}$ did not differentiate between the presence or absence of diabetic peripheral neuropathy. Hence the diagnostic accuracies were not specific to clinical neuropathy. In the second study, ${ }^{8}$ the Vibratip was further compared with the neurothesiometer, which is considered the gold standard for assessment of peripheral neuropathy. The study used receiver operating characteristic curves to compare results between the neurothesiometer and those of 
the VibraTip, tuning fork, monofilament and Neurotip. The results were then compared using the intra-rater reliability. The strength of this study 8 is that all sites commonly used for testing for vibration as part of screening for diabetic peripheral neuropathy were evaluated. Hence by constructing receiver operating characteristic curves, the best performance of each of the bedside tools was known prior to comparison with the neurothesiometer set at 25 Volts. ${ }^{9}$ However the weakness of this study ${ }^{8}$ is the comparison of devices assessing different modalities of sensory loss (vibration, touch, pain) in peripheral neuropathy.

The sensitivity of the VibraTip is more than double that of the tuning fork in PN +ve subjects. This suggests VibraTip is more reliable than the tuning fork in bedside evaluation of peripheral neuropathy. Although the tuning fork has a higher specificity than the VibraTip, these values are not statistically significant. Hence the VibraTip would have a better utility compared to the tuning fork in the assessment of loss of vibration sense from diabetic peripheral neuropathy.

\section{Conclusions}

The results of the present study support those of previous studies.7,8 The VibraTip has diagnostic accuracy comparable to the neurothesiometer. It can be used in daily clinical use for screening for diabetic peripheral neuropathy. However correlation with other signs would be needed for completeness. Nerve conduction studies would confirm diagnosis.

Acknowledgements The authors would like to thank Dr K. Shotliff and Dr D. Morganstein for assisting in recruiting patients to the study.

\section{Conflict of interest None}

Funding sources Chelsea \& Westminster NHS Foundation Trust Research and Development Department

Patient consent Informed consent obtained

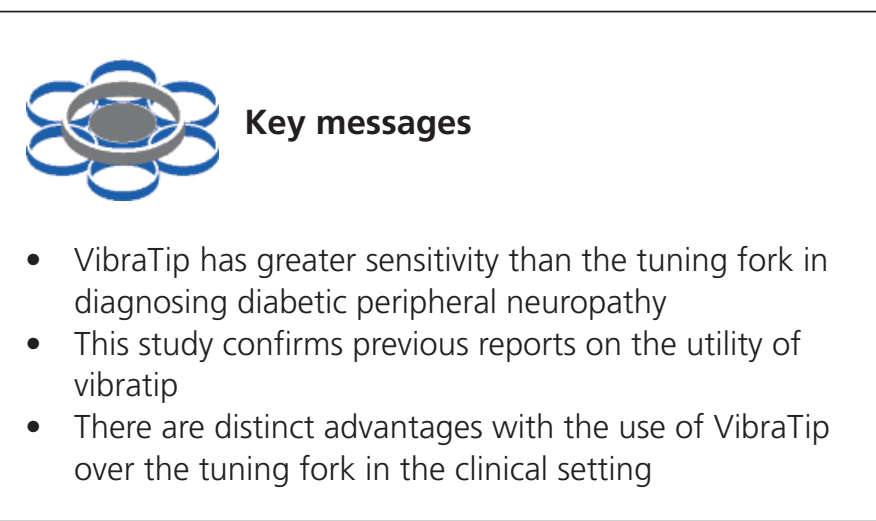

\section{References}

1. Rumpf H. Uber einen Fall von Syringomyelie nebst Beitrag zur Untersuchung der Sensibilitat. Neurologisches Zentralblatt 1889.

2. Lewandowsky M. Handbuk der Neurologie.Bd 1. Allg. Neurologie 11. Berlin: Spinger, 1910: 499-502.

3. Freeman C, Okun, M S. Origin of the sensory examination in neurology. Semin Neurol 2002;22:399-407. http://dx.doi.org/10.1055/s-2002-36762

4. Juma A, Mandal A. Vibration sensitivity testing with tuning fork: $256 \mathrm{~Hz}$ or $512 \mathrm{~Hz}$ ? Eur J Plastic Surg 2007;30:5-6. http://dx.doi.org/10.1007/s00238-007-0125-y

5. Bril V, Kolic J, Ngo M, et al. Comparison of a neurothesiometer and vibration in measurement of vibration perception thresholds and relationship to nerve conduction studies. Diabetes Care 1997;20:1360-2. http://dx.doi.org/10.2337/diacare.20.9.1360

6. www.vibratip.com (Accessed February 2014).

7. Levy A. Preliminary data on Vibratip, a new source of standardized vibration for bedside assessment of peripheral neuropathy. $\mathrm{Br} J$ Diabetes Vasc Dis 2010;10:284-6. http://dx.doi.org/10.1177/1474651410390741

8. Bracewell N, Game F, Jeffcoate W, Scammell BE. Clinical evaluation of a new device in the assessment of peripheral sensory neuropathy in diabetes. Diabet Med 2012;29:1553-5. http://dx.doi.org/10.1111/j.1464-5491.2012.03729.x

9. Bowling FL, Abbott CA, Harris WE Atanasov S, Malik RA, Boulton AJ. A pocket size device for testing the integrity of sensation in the outpatient setting. Diabet Med 2012;29:1550-2.

http://dx.doi.org/10.1111/j.1464-5491.2012.03730.x 